\title{
アクロボットの振り上げ倒立制御と特異点問題
}

\author{
南 澤 槿* 美 多 勉* Ioannis Pantelidis* 山北 昌 毅*
}

\section{Swing-up Control and Singular Problem of an Acrobot System}

Taek-Kun Nam*, Tsutomu Mita*, Ioannis Pantelidis* and Masaki Yamakita*

\begin{abstract}
We described a technique for the swingup control of a 2 link acrobat robot using backstepping and discussed singular problems.
\end{abstract}

Key Words: Nonholonomic System, Acrobat Robot, Swing up Control

1. は じめに

劣駆動系は一般化座標の数より少ない数のアクチュエータで 一般化座標全部を制御する機構である [1]. 特に, 根元に駆動関 節を待たないマニピュレータはアクロボットと呼ばれ，鉄棒選 手などの簡略化されたモデルとしても用いられている。本論文 は，2リンクアクロボットを使い，懸垂姿勢から振り上げ動作 を経て倒立姿勢を実現するための新しい制御法の提案とシミュ レーション結果に関して述べたものである.

アクロボットの振り上げや倒立に関する従来の研究を見ると， Spong [4] らは単振動する Zero Dynamics や Pumping エネル ギー関数を用いて振り上げ倒立制御を行っている。しかし，前者 は過大な入力が必要となり, また, 収束も遅く, 後者は収束する までの時間が極端に長い. Hauser [3] らは, 平衡マニフォール ド内で線形化されたシステムと等価な近似非線形システムを構 成し，倒立制御について論じている。しかし，収束性が悪い。 方, Saber [5] [6] はアクロボットの直列表現を提案し，さらに陰 関数定理を使った Backstepping 制御則による振り上げ倒立制 御を提案している.しかし，除関数定理に基づいて入力となる関 数を逆算するのは困難であり, Saber 自身も具体的な制御則を 明示していない. 実は, この直列表現は我々が独立に開発してき た，角運動量表現による正準系 [1] と重心角による2 リンク浮遊 ロボットの表現 [1] 統合したものである。一方，Cambrini [7] は歩行機械において角運動量に安定な Zero Dynamics を加え た変数を制御することにより，倒立制御を実現しようとしてい る.これらの研究の目的はほほ同一であるが，“制御途中で入力 が発散してしまう特異点の出現”, “運動が原点以外の平衡マ二 フォールドで止まってしまう”，という問題が共通にある。しか し, 特異点問題は以上で引用した論文では言及されていない。

原稿受付 2000 年 9 月 18 日

*東京工業大学

${ }^{*}$ Tokyo Insititute of Technology
本論文では，まず，制御系の表現として直列制御系を Saber の方法とは独立に直接的に導く。そして，角運動量を零にする 制御則（以下，制御則 A とする）をまず検討する。 その結果, 特異平面が存在し，懸垂姿勢から倒立制御を一つの制御で行う のは難しいことが分かり，制御を正弦波入力による振り上げ，角 運動量を 0 にする制御, 線形近似制御の繰り返しの 3 段階で行 うとよいことをまず示す。

次に，第 $2 ， 3$ 段階の制御を一つの制御則で行える可能性があ る Cambrini らの提案に基づく方法（以下，制御則 $\mathrm{B}$ とする) について, 特異点問題を検討する。そして, 角運動量が零でな い場合には制御則 $\mathrm{A}$ の場合より条件が厳しく，2，3段階を一 つにまとめて行うのは難しいと判断されることを述べる。そこ で, 制御則 A で角運動量を一度零にしておいてから, 線形近似 制御の繰り返し適用の代わりに，この制御を使うと第 3 段階の 制御が短時間で行えることを示す，すなわち，本論文としては， 特異点問題を解析した結果，正弦波入力による振り上げ，制御 則 $\mathrm{A}$ ，制御則 $\mathrm{B}$ の 3 段の適用を提案する.

\section{2. 制御対象と直列系の導出}

Fig.19ような重力場での 2 リンクロボットを制御対象とす る.このロボットにおいて，第 1 ，第 2 リンクの質量をそれぞ れ $m_{1}, m_{2}$, 長さを $l_{1}, l_{2}$, 第 1 関節から第 1 リンクの重心まで の距離を $a_{1}$, 第 2 関節から第 2 リンクの重心までの距離を $a_{2}$, 重心回りの慣性モーメントを，それぞれ $J_{1}, J_{2}$ とする，また， $\theta$ は第 1 リンクの絶対角, $\psi$ は第 2 リンクの相対角とする。

ここで，第 1 関節を非駆動関節とすると，このロボットの運 動方程式は

$$
\begin{aligned}
& (\alpha+\gamma+2 \beta \cos \psi) \ddot{\theta}+(\gamma+\beta \cos \psi) \ddot{\psi}-\beta \dot{\psi}(2 \dot{\theta}+\dot{\psi}) \sin \psi \\
& \quad+k_{1} \cos \theta+k_{2} \cos (\theta+\psi)=0 \\
& (\gamma+\beta \cos \psi)+\gamma \ddot{\psi}+\beta \dot{\theta}^{2} \sin \psi+k_{2} \cos (\theta+\psi)=\tau_{2}
\end{aligned}
$$


Ioannis Pantelidis 山北昌 毅

となる $[1]$. ただし， $\tau_{2}$ は $\psi$ を駆動するトルクであり

$$
\begin{aligned}
& \alpha=J_{1}+m_{1} a_{1}^{2}+m_{2} l_{1}^{2}, \beta=m_{2} l_{1} a_{2}, \gamma=J_{2}+m_{2} a_{2}^{2} \\
& k_{1}=\left(m_{1} a_{1}+m_{2} l_{1}\right) g, k_{2}=m_{2} a_{2} g
\end{aligned}
$$

である. 制御目的は $\theta=-\pi / 2, \psi=0$ の懸垂状態から振子を 振り上げ， $\theta=\pi / 2, \psi=0$ で倒立させることである.

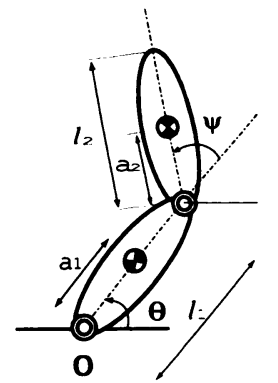

Fig.1 Acrobat robot まず, 制御則を求めるのに便利 なように, $\dot{\theta}, \dot{\psi}, \theta, \psi$ の非線形 フィードバックと新しいトルク 入力 $u$ にって式 (2) を部分 線形化すれば [1] [4], 以下のよ うに簡略化され，

$$
\ddot{\psi}=u
$$

式（1）は積分できない加速度 拘束となる $[2]$. ただし, 角運動 量を持ち込むことによって, 式 (1) は 1 階の微分方程式で表す ことができる.すなわち, 回転軸 $O$ 点回りの角運動量 $P$ を求 めると

$$
P=(\alpha+\gamma+2 \beta \cos \psi) \dot{\theta}+(\gamma+\beta \cos \psi) \dot{\psi}
$$

となり，本式を微分してみると，式（1）が

$$
\dot{P}=-k_{1} \cos \theta-k_{2} \cos (\psi+\theta)
$$

となっていることが分かる.これは, 回転軸 $O$ 回りの角運動量 の増分がリンクの姿勢変化に伴う重力変化に影響されることを 意味している。また，式（4）から

$$
\dot{\theta}=\frac{P}{(\alpha+\gamma+2 \beta \cos \psi)}-\frac{(\gamma+\beta \cos \psi)}{(\alpha+\gamma+2 \beta \cos \psi)} \dot{\psi}
$$

も得られる.さらに本式第 2 項を 0 とするため

$$
\begin{aligned}
z & :=\theta+\int_{0}^{\psi} \frac{\gamma+\beta \cos \psi}{\alpha+\gamma+2 \beta \cos \psi} d \psi-\pi / 2 \\
& :=\theta+w(\psi)
\end{aligned}
$$

の座標変換を行えば

$$
\dot{z}=\frac{P}{\alpha+\gamma+2 \beta \cos \psi}
$$

と簡単化でき, $z$ は $\theta=\pi / 2, \psi=0$ の目標点で 0 となる変数 となる。この $z$ は文献 [1] で重心角と呼んだ変数である.

そこで, 状態変数を $q=(z, P, \psi, \dot{\psi})^{T}$ としてまとめれば,

$$
\begin{aligned}
& {\left[\begin{array}{c}
\dot{z} \\
\dot{P} \\
\dot{\psi} \\
\ddot{\psi}
\end{array}\right]=\left[\begin{array}{c}
P / h(\psi) \\
d(z, \psi) \\
\dot{\psi} \\
0
\end{array}\right]+\left[\begin{array}{l}
0 \\
0 \\
0 \\
1
\end{array}\right] u} \\
& \text { ただし, } \\
& h(\psi)=\alpha+\gamma+2 \beta \cos \psi>0 \\
& d(z, \psi)=-k_{1} \cos (z-w(\psi))-k_{2} \cos (z-w(\psi)+\psi)
\end{aligned}
$$

化する制御則を求めれば，Backsteppingによってトルク入力 $u=\ddot{\psi}$ が求まることが期待される. 奉際, Saber ら [5] [6]はそ のような提案をし，陰関数定理から入力を求めようとしている が，具体的な制御則は求められていない.

\section{3. 振り上げ倒立制御}

\section{1 制御則 $\mathbf{A}$}

Backstepping では最終的にトルク入力 $u$ を求めるため，ま ず，角速度 $v=\dot{\psi}$ を入力として扱い, 式 (9) を

$$
\left[\begin{array}{c}
\dot{z} \\
\dot{P} \\
\dot{\psi}
\end{array}\right]=\left[\begin{array}{c}
P / h(\psi) \\
d(z, \psi) \\
0
\end{array}\right]+\left[\begin{array}{l}
0 \\
0 \\
1
\end{array}\right] v
$$

としておく.この系に対して，ここでは $P$ が

$$
\ddot{P}+f_{2} \dot{P}+f_{1} P=0
$$

を満たすような $v$ を求める。 ただし， $f_{1}>0, f_{2}>0$ は設計 パラメータである。これは,

$$
V_{1}=\left(\dot{P}^{2}+f_{1} P^{2}\right) / 2
$$

のリアプノフ関数に対して

$$
\dot{V}_{1}=\dot{P}\left(\ddot{P}+f_{2} \dot{P}+f_{1} P\right)-f_{2} \dot{P}^{2}=-f_{2} \dot{P}^{2} \leq 0
$$

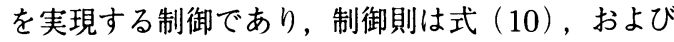

$$
\ddot{P}=\frac{\partial d}{\partial z} \frac{P}{h}+\frac{\partial d}{\partial \psi} v
$$

を式（11）に代入して

$$
v=F_{1}(z, P, \psi)=-\left(\frac{\partial d}{\partial \psi}\right)^{-1}\left(\frac{\partial d}{\partial z} \frac{P}{h}+f_{2} d+f_{1} P\right)
$$

として求められる. $v$ が求まったので, 積分型 Backstepping [8] により $u$ を求めよう。このため, $v-F_{1}$ が零でなく，したがっ て，式（11）が成り立っていないと仮定し

$$
V_{2}=V_{1}+\left(v-F_{1}\right)^{2} / 2>0
$$

に対して $\dot{V}_{2}$ を半負定にするトルク入力 $u$ を求める。すると, $\dot{v}=u$ と式（14）から

$$
\begin{aligned}
\dot{V}_{2}= & \dot{P}\left(\ddot{P}+f_{1} P\right)+\left(u-\dot{F}_{1}\right)\left(v-F_{1}\right) \\
= & \dot{P}\left\{(\partial d / \partial z)(P / h)+(\partial d / \partial \psi) v+f_{1} P\right\} \\
& +\left(u-\dot{F}_{1}\right)\left(v-F_{1}\right) \\
= & \dot{P}\left\{(\partial d / \partial z)(P / h)+(\partial d / \partial \psi)\left(v-F_{1}+F_{1}\right)+f_{1} P\right\} \\
& +\left(u-\dot{F}_{1}\right)\left(v-F_{1}\right) \\
= & \dot{P}\left\{(\partial d / \partial z)(P / h)+(\partial d / \partial \psi) F_{1}+f_{1} P\right\} \\
& +\left(u-\dot{F}_{1}+(\partial d / \partial \psi) d\right)\left(v-F_{1}\right)
\end{aligned}
$$

とおけ，さらに，式（15）の $F_{1}$ の定義と $d \dot{P}=\dot{P}^{2}$ を使い

$$
\dot{V}_{2}=-f_{2} \dot{P}^{2}-f_{3}\left(v-F_{1}\right)^{2} \leq 0
$$

となるように $u$ を選べば 


$$
u=\dot{F}_{1}-f_{3}\left(v-F_{1}\right)-\frac{\partial d}{\partial \psi} d
$$

となる，ただし， $f_{3}>0$ は設計パラメータである.

ただし， $V_{2}\left(V_{1}\right)$ は半負定なので, 状態は

$$
P=0, \quad \dot{P}=-k_{1} \cos \theta-k_{2} \cos (\psi+\theta)=0
$$

を満たす平衡マニフォールドで静止する。これは，軸受けの真 上にロボットの重心がある姿勢となる，以下，これを状態 $\mathrm{M}$ (status M) と呼ぶ.この状態は Fig. 2 の実線のように, $\theta-\psi$ 平面の曲線を描く。

一度，状態 $\mathrm{M}$ に達したら， $\theta=\pi / 2, \psi=0$ の倒立制御に関 しては，平衡点を少しづつ上げていく線形近似制御を採用する ことが考えられる $[1]$.

特に, 式（15）において入力を発散させる特異点は $\partial d / \partial \psi=0$ から

$-k_{1} \sin \theta(\gamma+\beta \cos \psi)+k_{2} \sin (\theta+\psi)(\alpha+\beta \cos \psi)=0$

を満たす $\theta-\psi$ 平面の曲線群となる。この特異曲線を Fig. 2 に 点線で示す.これから, 少なくとも $\theta(0), \psi(0)$ は二つの特異曲 線内になくてはならない．なお，入力をトルクに変えても新し い特異点は現れない。この特異曲線の存在のため, 式 (19) た けに頼っては，懸垂状態からの倒立制御は不可能であることが 分かる. なぜなら， $(\theta, \psi)=(-\pi / 2,0),(\pi / 2,0)$ の間を特異曲 線が走っているからである，そこで，懸垂状態から特異曲線内 部までの状態推移に関しては, 入力 $u$ として正弦波を加え, 多 少の試行錯誤でその振幅や大きさを決めた。シミュレーション 結果は次章で示す.

\section{2 制御則 B}

次に線形近似制御を使わない方法を示す．前節のように, $P$ だけを式（11）を満たすように安定化しても一次の Zero Dynamics（積分型）が残り，状態は式 (20)にとどまり，直接的 に $z=0(\theta=\pi / 2)$ を実現することはできない.

そこで, Cambrini [7] らが歩行ロボットの研究で提案してい るように

$$
y=P+L z
$$

を $P$ に代わる制御量とし

$$
\ddot{y}+c_{2} \dot{y}+c_{1} y=0
$$

として安定化することを考える. ただし $, c_{1}>0, c_{2}>0, L>0$

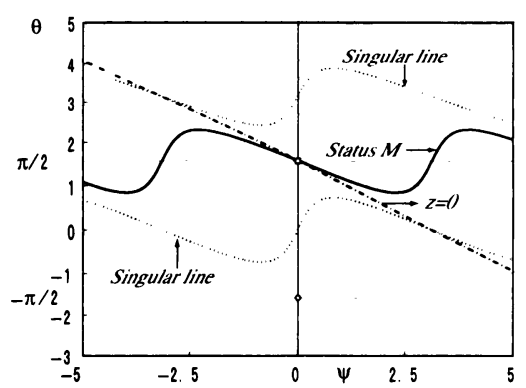

Fig. 2 Equilibrium and singular lines
は設計パラメータである。この場合, 式 (10) から, $\dot{z}=P / h$ が成り立つので, $y=0$ は

$$
y=h(\psi) \dot{z}+L z=0
$$

に等しく, $h(\psi)>0$ から $z$ は安定となり, $z=0(\theta=\pi / 2)$ へ の漸近が保証される。一方， $z=0$ となった場合，状態は

$$
z=\theta+w(\psi)=0
$$

を満たす別の平衡マニフォールドを構成する。このマニフォー ルドは Fig. 2 に一点鎖線で示したようになり，状態 M を満た すマニフォールドとの交点は $(\theta, \psi)=(\pi / 2,0)$ 唯一となる.さ らに, $y=0, z=0$ は $P=0$ を意味するので, 結局全変数が 安定化される。制御則は式 (22), 式 (10), 式 (14), および

$$
\ddot{z}=\frac{\dot{P}}{h}-\frac{(\partial h / \partial \psi) P v}{h^{2}}
$$

を式（23）に代入して

$$
\begin{aligned}
v= & F_{2}(z, P, \psi) \\
= & -\left(\frac{\partial d}{\partial \psi}-\frac{(\partial h / \partial \psi) P L}{h^{2}}\right)^{-1} \\
& \times\left(\frac{\partial d}{\partial z} \frac{P}{h}+\frac{L d}{h}+c_{2}\left(d+\frac{L P}{h}\right)+c_{1}(P+L z)\right)
\end{aligned}
$$

となる，トルク入力 $u$ を使う場合，Backstepping を行えば

$$
u=\dot{F}_{2}-c_{3}\left(v-F_{2}\right)-\left(\frac{\partial d}{\partial \psi}-L \frac{(\partial h / \partial \psi) P}{h^{2}}\right) \dot{y}
$$

となる。これを制御則 $\mathbf{B}$ とする。

ただし，v を発散させる特異点が

$$
\frac{\partial d}{\partial \psi}-\frac{(\partial h / \partial \psi) P L}{h^{2}}=0
$$

を満たす平面 $(\theta, P, \psi)$ となり， $P$ に制約が生ずる. Fig. 3 に は $L=1$ で $P$ を 010 変えた場合の特異平面を $\theta-\psi$ 平面

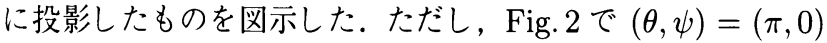
を通る特異曲線に対応するもののみが示されている（Fig. 2 の 点線は $P=0$ の場合に対応する)。これから， $P$ が大きくなる と隣あった特異曲線が近づき， $\theta, \psi$ の動作範囲が極度に制約 されることが分かる。このため, 制御則 $\mathrm{B}$ を使っても, 状態 $\mathrm{M}$ への収束, 線形近似制御を一つにまとめることは困難であった。

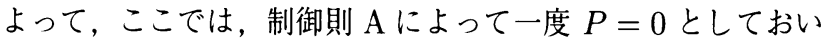
てから, 線形近似制御の繰り返しに代えて制御則 B を使うこと を提案する.すなわち, 正弦波入力, 制御則 $\mathrm{A}$, 制御則 $\mathrm{B}$ の三 つを順に適用することを提案する。

\section{4. シミュレーション結果}

以上の結果に基づいて静止懸垂姿勢 $(\theta, \psi)=(-\pi / 2,0)$ か ら倒立姿勢 $(\theta, \psi)=(\pi / 2,0)$ までの制御のシミュレーショ ンを行った。 パラメー夕は $m_{1}=1[\mathrm{~kg}], m_{2}=1[\mathrm{~kg}], l_{1}=$ $1[\mathrm{~m}], l_{2}=2[\mathrm{~m}], a_{1}=0.5 l_{1}, a_{2}=0.5 l_{2}, g=9.8\left[\mathrm{~m} / \mathrm{s}^{2}\right], J_{1}=$ $0.0833\left[\mathrm{kgm}^{2}\right], J_{2}=0.3333\left[\mathrm{kgm}^{2}\right]$ とした. 第 1 ステップの制 


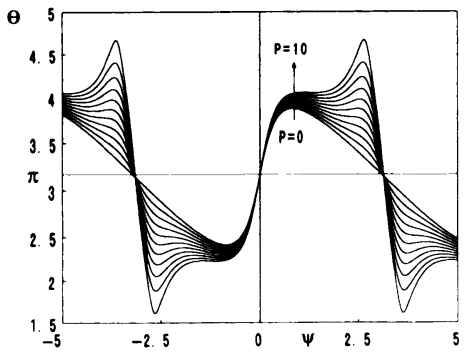

Fig. 3 Singular line with the change of $P$

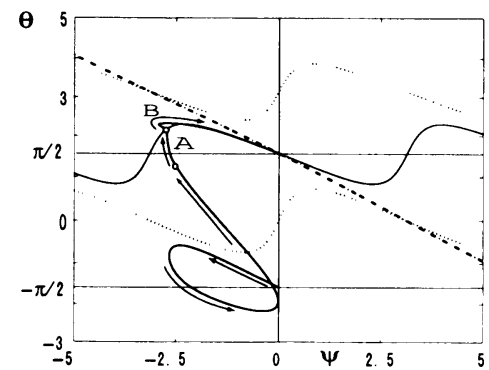

Fig. 4 Trajectory of the states $\psi$ and $\theta$

御入力は $u=-12 \cos (3 t)$ とした. 制御則 $\mathrm{A}$, 制御則 Bへの切 り換え時間はそれぞれ $t_{1}=3.1(s), t_{2}=5(s)$ であり, フィー ドバックゲインは $f_{1}=c_{1}=9, f_{2}=c_{2}=6, f_{3}=c_{3}=8$, $L=3$ とした。

Fig. 4 は状態変数 $\psi, \theta$ の解軌道を特異曲線と共に表したも のであり，○印の 2 個所で三つの制御を切りかえている. 正弦 波の振り上げ制御で軌道が特異曲線内に入ることが分かる。 た だし, 状態の軌道 $(\theta-\psi)$ を特異曲線内に移動させるため必要 な正弦波入力の振幅と周期は試行錯誤を通して決めた. Fig. 5 は閉ループ系の状態変数とトルク入力の応答であり, Fig. 6 は シミュレーション結果を動画に表したものであり, 図中の小さ な黒丸はロボットの重心を表している. 図からは目標とする倒 立姿勢が達成されていることが分かる.

\section{5.おわりに}

アクロボットの振り上げ倒立制御に関して特異点を解析し, 新 しい制御則を提案し, シミュレーションによって有効性を検証 した.

\section{参 考 文 献}

[1] 美多: 非線形制御入門一劣駆動ロボットの技能制御論一. 昭晃堂, 2000 .

[2] G. Oriolo and Y. Nakamura: "Control of Mechanical Systems with Second-Order Nonholonomic Constraints: Underactuated Manipulators," in Proc. of IEEE CDC, pp.2398-2403, 1991.

[3] J. Hauser and R.M. Murray: "Nonlinear controllers for nonintegrable systems: the Acrobot example," Proc. of IEEE CDC, pp.669-671, 1996.

[4] M. Spong: "The swing up control problem for the acrobot, IEEE Control Systems Magazine," vol.15, no.2, pp.49-55, 1995.

[5] R.O. Saber and A. Megretski: "Controller design for a class of underactuated nonlinear Systems," Proc. IEEE CDC, pp.41824186, 1988.

[6] R.O. Saber: "Control of Underactuaed Mechanical Systems

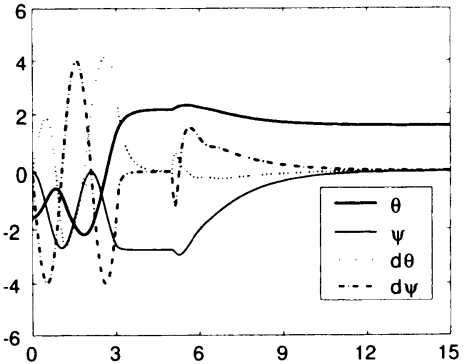

(a) Time evolution of states (I)

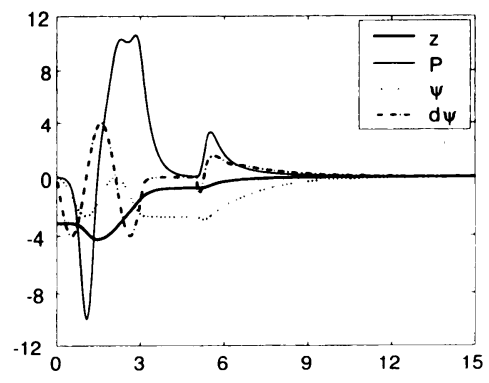

(b) Time evolution of states (II)

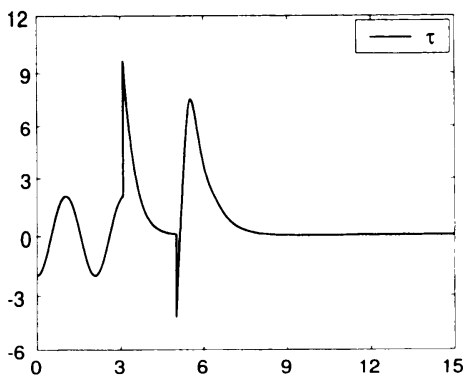

(c) Time evolution of torque

Fig. 5 Simulation

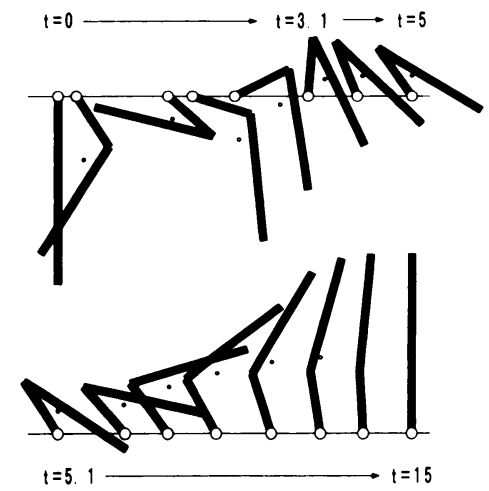

Fig. 6 Animation of swing up control

with Two Degrees of Freedom and Symmetry," in Proc. of ACC, pp.4092-4096, 2000 .

[ 7 ] L. Cambrini, C. Chevallereau, C.H. Moog and R. Stojic: "Stable Trajectory Tracking for Bied Robots," Proc. of IEEE CDC, pp.4815-4820, 2000.

[ 8 ] H.K. Khalil: Nonlinear Systems. Prentice Hall, 1996. 